\title{
Effect of Insulin on Blood Sugar Levels of Fishes*1
}

\author{
Masayuki FURUICHI and Yasuo YONE*2 \\ (Received January 21, 1982)
}

\begin{abstract}
Carp Cyprinus carpio, red sea bream Chrysophrys major, and yellowtail Seriola quinqueradiata were subjected to an insulin sensitivity test and to an insulin-glucose tolerance test, in order to investigate the reason why the fish had a low capability of utilizing carbohydrate. The intramuscular injection of insulin not only decreased blood sugar levels during fasting but also suppressed the increases of blood sugar levels after the administration of glucose. These results suggest that the low utilization of carbohydrate by fishes may be caused by an absolute insufficiency of insulin.
\end{abstract}

Previous papers ${ }^{1-3)}$ indicated that the capability of utilizing carbohydrate by fishes was lower than that of domestic animals and differed between the fish species. Furthermore, it was presumed from the results of previous studies ${ }^{3,4)}$ that the low utilization of carbohydrate is primarily attributable to the insufficiency of insulin secretion. In the present paper, therefore, in order to investigate whether the low capability of utilizing carbohydrate by fishes is attributed to the absolute insufficiency of insulin, or to the relative insufficiency resulting from an excess of insulin-antagonists, fishes were subjected to the insulin sensitivity test and the insulin-glucose tolerance test.

\section{Experimental Methods}

\section{Insulin Sensitivity Test}

Carp weighing 83 to $108 \mathrm{~g}$, red sea bream weighing 68 to $84 \mathrm{~g}$, and yellowtail weighing 55 to $110 \mathrm{~g}$ were subjected to the insulin sensitivity test, after a 2-week feeding on a compounded feed, beef liver, and jack mackerel, respectively. Namely, 1 IU of bovine insulin ("ISZILIN" produced by Shimizu Seiyaku Co. Ltd.) per $100 \mathrm{~g}$ body weight was intramuscularly injected to each fish which was starved for 24 hours. 3 to 5 fish from each group were sampled at random before and at 15-, 30-, 45-, 60-, 120-, and 180-minute periods after the injection of insulin. Blood was taken from the Cuvierian duct, and blood sugar content was determined by the method of Momose et al. ${ }^{5}$ )
Carp and red sea bream were reared in $150 l$ aquariums $(90 \times 45 \times 45 \mathrm{~cm})$ and yellowtail in a round tank of 3 ton capacity (Diameter $2 \mathrm{~m} \times$ Depth $1 \mathrm{~m}$ ).

\section{Insulin-Glucose Tolerance Test}

Carp, red sea bream, and yellowtail which were fed the diets with and without dextrin for 30 days in the previous study ${ }^{2}$ were used for the insulinglucose tolerance test. The test was the same as described previously. ${ }^{\text {) }}$ A random sampling of 4 to 5 fish from each group was made before and at 1-, 2-, 3-, and 5-hour periods after the administration of insulin and glucose, and blood from the Cuvierian duct was presented for the determination of blood sugar content.

\section{Results and Discussion}

As shown in Fig. 1, blood sugar contents of carp and red sea bream decreased immediately after the injection of insulin, and was maintained at lower levels than that of each control fish without insulin injection during 30-minute period to 3-hour period. The blood sugar levels of yellowtail also decreased by the injection of insulin, but the start of decreasing seemed to be later than carp and red sea bream.

When insulin and glucose were administered, blood sugar levels of fishes increased slightly at 1-hour period after the administration, but decreased thereafter and exhibited similar values to

*1 Contribution from Fish. Res. Lab., Kyushu Univ., No. 153. This work was supported in part by Grantin-Aid for Encouragement of Young Scientist (Grant No. 176129) from the Ministry of Education, Science and Culture of Japan.

*2 Fish. Res. Lab., Kyushu Univ., Tsuyazaki, Fukuoka 811-33, Japan（古市政幸・米 氺夫：九州大学震学 部附属水産実験所)。 


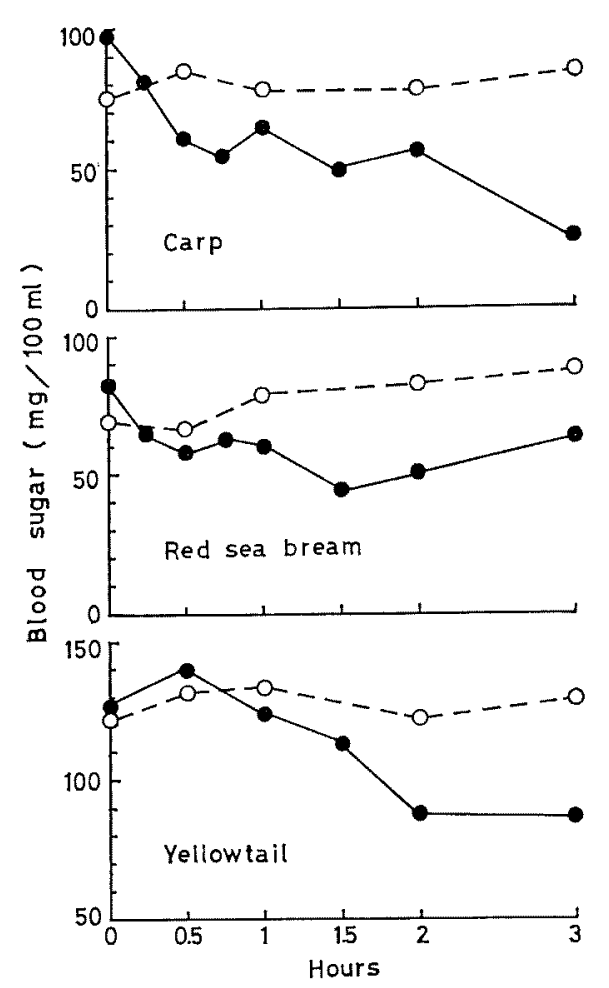

Fig. 1. Change in blood sugar levels of fishes subjected to an insulin sensitivity test.

Each value is average of 3 to 5 fish.

- Injected $1 \mathrm{IU}$ insulin per $100 \mathrm{~g}$ body weight.

- Control (without insulin injection).

or lower values than the fasting levels after 3-hour period, in all groups (Fig. 2). Namely, the intramuscular injection of insulin suppressed the increasing of blood sugar levels of fishes after the administration of glucose. Such suppressive action of insulin to the increase of blood sugar levels has also reported by several workers. ${ }^{7-12}$ )

Accordingly, these results suggest that the amount of insulin-antagonists may be only a little if any existed in the fishes, and that the low utilization of carbohydrate by fishes be caused by the absolute insufficiency of insulin.

\section{References}

1) M. Furuichi, K. Shitanda, and Y. Yone: Rep. Fish. Res. Lab., Kyushu Univ., No. 1, 91-100 (1971).

2) M. Furutch and Y. Yone: Bull. Japan. Soc. Sci. Fish., 46, 225-229 (1980).
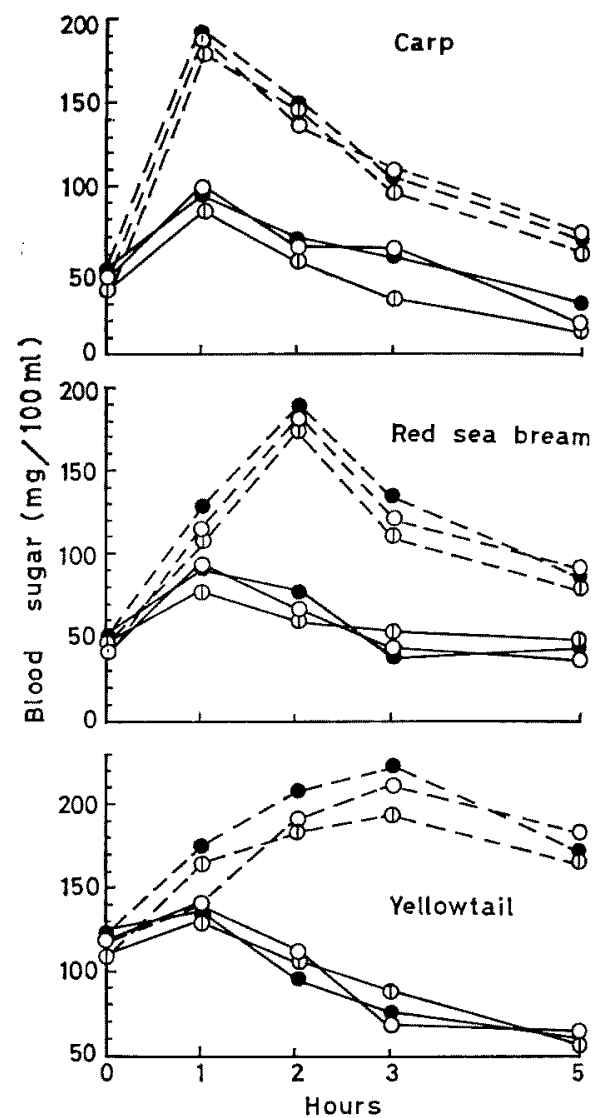

Fig. 2. Change in blood sugar levels of fishes, which were reared on the diets with and without dextrin, in an insulin-glucose tolerance test.

Each value is average of 4 to 5 fish.

- Injected $1 \mathrm{IU}$ insulin per $100 \mathrm{~g}$ body weight and administered $167 \mathrm{mg}$ glucose per $100 \mathrm{~g}$ body weight.

-...- Control (administered only glucose).

Dextrin-free diet group,

(1) $10 \%$ dextrin diet group,

- $40 \%$ dextrin diet group.

3) M. Furuichi and Y. Yone: Bull. Japan. Soc. Sci. Fish., 47, 761-764 (1981).

4) M. Furuich and Y. YONE: Rep. Fish. Res. Lab., Kyushu Univ., No. 1, 101-106 (1971).

5) T. Momose, Y. Yano, and K. Ohashi: Chem. Pharm. Bull., 11, 968-972 (1963).

6) M. FuruichI and Y. Yone: Bull. Japan. Soc. Sci. Fish., 48, 463-466 (1982).

7) I. E. Gray and F. G. Hall: Biol. Bull., 58, 217-223 (1930).

8) S. Falkmer and A. J. Matty: Gen. Comp. Endocrinol., 6, 334-346 (1966). 
9) L. Leibson and E. M. Plisetskaya: Gen. Comp. Endocrinol., 11, 381-392 (1968).

10) L. TAShima and G. F. CAHLL, JR.: Gen. Comp. Endocrinol., 11, 262-271 (1968).
11) M. Yoкоте: Bull. Japan. Soc. Sci. Fish., 36, 1219-1223 (1970).

12) Y. InU and M. Yokote: Bull. Japan. Soc. Sci. Fish., 41, 965-972 (1975). 